The Physical Examination of Metals

By Dr. Bruce Chalmers and Dr. A. G. Quarrell. Vol. 2: Electrical Methods. Pp. viii $+280+8$ plates. (London: Edward Arnold and Co., 1941.) 20s, net.

TN Vol. 1 (reviewed in Nature, 145, 660; 1940), 1 Dr. Chalmers described optical methods of metallurgical investigation. In the present volume, he unites with Dr. Quarrell, a pioneer in the development of electron diffraction research in metallo. graphy, to deal with electrical methods, thus completing a work which will be a boon to the research worker and an indispensable part of students' reading.

The scope of vol. 2 is reviewed in its first chapter. It is logically planned, commencing with magnetic properties and their measurements. Electric measurements and thermo-electric effects are then discussed. $\mathrm{X}$-ray diffraction technique, as applied to metallurgy, is then dealt with and electron diffraction methods follow. The present position of electron microscopy is then examined. The final chapter deals briefly with radiography. Appendixes are devoted to electrolytic polishing and X-ray crystallographic data.

This book successfully combines theoretical treatment with practical outlook. The authors have certainly succeeded in their attempt "to indicate the scope and limitations of the various methods . . . by reférence to successful applications". One application, hitherto unpublished, is a very pretty microthermal analysis (p. 108), for which Dr. Chalmers managed to do without any gramophone needles.

Perhaps because it is regarded as engineering rather than metallurgy, stress analysis is not dealt with in the discussion of X-ray diffraction methods.

H. W. G. H.

Modern Assembly Processes

Their Development and Control. By J. L. Miller. Pp. xii $+168+28$ plates. (London: Chapman and Hall, Ltd., 1941.) 13s. 6d. net.

T is possibly strange that engineers have had to wait so long for a book dealing specifically with jointing methods used in the large-scale production of small parts. So far as Great Britain is concerned, it is probable that everybody has waited for $\mathbf{M r}$. Miller to write it. Those readers who have not the good fortune to know the author personally, will learn from this book that he is a first-class engineer of very long practical experience and gifted with the intelligent curiosity and enthusiasm which most people lose when they gain years of discretion. Those who do know him will enjoy meeting him again in these pages, packed with common sense, and will take particular pleasure in the simple logic with which each point is explained.

The processes dealt with are riveting, soft soldering, hard soldering and brazing, hydrogen furnace brazing, pressure and shrinkage fits, fusion welding by gas and arc methods and electrical resistance welding. The advantages and limitations of each method of jointing are clearly stated and the fundamental principles, on which a choice should be based, are admirably stressed. The chapters on hydrogen furnace brazing and projection welding are unique, since the author has had unique experience in developing and applying these processes; but there are few chapters in which the most up-to-date engineer will not find something useful, and the wisdom of Chapter 14, "Testing, Inspection and Trouble Hunting", is worth every penny of the book's purchase price.

\section{Polynesian Paradise}

An Elaborated Travel Journal, based on Ethnological Facts. By Donald Sloan. Pp. $288+15$ plates. (London: Robert Hale, Ltd., 1941.) 12s. 6d. net.

7 HIS book is a departure from the usual type of story from the South Seas in that it contains quite a lot of information that will interest an anthropologist. The author lived for several months on Manu'au, an isolated group of three volcanic islands inhabited by Polynesians of Samoan stock. These islands are off the usual routes and their isolation has been jealously guarded by the United States of America, to whom they belong, in order to preserve their integrity. This is the more easily done as the Manu'ans themselves are a conservative race and cling to their old ways of life.

By living among them as he did, the author was able to enter freely into their daily life, and he obviously made good use of his opportunities. As a personal guest of the chief he was present, and partook of, all the important feasts and ceremonies, including those for the burial of the chief and the marriage of the village virgin. He gives full accounts of these as well as of the daily life of these unsophiscicated people, with whom he was evidently on excellent terms. While there he learned, among other things, to fight with and kill a shark single. handed and armed only with a sharp knife : dealing thus with a seven-foot man-eater provides a truly Homeric contest.

Natives such as these Manu'ans who dwell in isolated parts and live out their lives in the old traditional way are always an interesting study, and although this book is perhaps more adventurous than deeply scientific, it may be none the worse for that as it is likely to interest a wider circle of readers in an extremely important study-that of the unspoilt native peoples.

\section{Introductory Foods}

By Osee Hughes. Pp. vii+522. (New York: The Macmillan Company, 1940.) 12s. 6d. net.

\section{HIS book will be regarded as throwing interesting}

light on the impact of nutritional science on cookery practice in the United States. It shows how the American housewife has become 'food-conscious' and 'vitamin-conscious', and why she has been diverted from the straight and honest path of Mrs. Glasse and Mrs. Beeton. The author has given quite a good scientific background to the hundred and one cooking problems he discusses. Vitamins, viscosity, surface tension, denaturation, crystal form are only a few of the scientific problems dealt with. 